\title{
CARACTERIZAÇÃO CONSTRUTIVA DE EDIFICAÇÃO DE ESCOLA PÚBLICA DE ENSINO FUNDAMENTAL I EM PRESIDENTE PRUDENTE-SP
}

Mariane Andrade Xavier (1); Willian Gomes Barbosa (1); Adauto Da Silva Jr (2); Sibila Corral De Arêa Leão Honda (3)

Universidade do Oeste Paulista - UNOESTE, Faculdade de Engenharias e Arquitetura e Urbanismo, Presidente Prudente, SP.

\section{RESUMO}

Durante o projeto estrutural e a execução de obra, a adequada definição do sistema construtivo é fundamental. Ao mesmo tempo, um sistema mal definido e/ou mal executado pode resultar em patologias da edificação. Dessa forma, o conhecimento e a análise desses sistemas torna-se primordial na formação do engenheiro civil. Focando nesse assunto, esta pesquisa buscou analisar questões sobre esse assunto, tendo como estudo de caso o edifício da escola pública municipal de ensino fundamental I Ivo Garrido, na cidade de Presidente Prudente, Estado de São Paulo. Interessante verificar que mesmo havendo definições legais sobre o sistema construtivo, essas não foram seguidas. A metodologia seguida foi qualitativa, baseada em aprofundamento teórico, levantamento físico, além de outros aspectos pertinentes.

Palavras Chave: Educação fundamental, Edificação, Sistema estrutural, Sistema construtivo.

\section{CONSTRUCTIVE CHARACTERISTICS OF PUBLIC ELEMENTARY SCHOOL BUILDING IN PRESIDENTE PRUDENTE-SP}

\begin{abstract}
During the structural design and execution of work, the appropriate setting of the building system is critical. At the same time, an ill-defined system and/or poorly executed construction can result in building pathologies. Thus, knowledge and analysis of these systems becomes paramount in the formation of civil engineer. Focusing on this subject, the objective of this research was to analyze issues on this subject, with case study on public elementary school building Ivo Garrido, in Presidente Prudente, state of São Paulo. It is interesting that even though there are legal definitions of constructive system, these were not obeyed. The methodology was qualitative, based on theoretical studies, physical survey, as well as other relevant aspects.
\end{abstract}

Keywords: Elementary education, Building, Structural system, building system. 


\section{INTRODUÇÃO}

O processo de construção depende de vários fatores, dentre eles, as definição do sistema construtivo. A partir desse, o sistema estrutural é caracterizado, barateando-se ou encarecendo-se uma obra, agilizando a construção ou atrasando os serviços. Ao mesmo tempo, tais definições também podem levar a inovações na área da engenharia e da construção civil.

No entanto, Medeiros (1990) afirma que o processo de inovações no setor da construção civil no Brasil se apresenta estagnado, sendo a parcela do setor industrial com maiores índices de atrasos. Ou seja, apesar do crescimento da curva do mercado imobiliário brasileiro nos últimos anos, manteve-se a produção de edificações com sistemas antigos e não otimizados.

Analisando a produção imobiliária por meio do setor público, verifica-se que este é grande consumidor e produtor. $\mathrm{E}$ análise dos processos construtivos torna-se interessante para identificar momentos históricos da construção civil brasileira. Ou seja, historicamente, pode-se verificar alterações nos projetos e na adoção de diferentes sistemas construtivos e estruturais.

Tais alterações podem ter relação com politicas nacionais ou estaduais, como no caso de novas edificações de ensino púbico, como alvenaria estrutural em edifícios mais antigos e prémoldado nos mais novos. Atualmente, visa-se à execução de unidades escolares de forma mais rápida e barata.

A partir disso, o objetivo desta pesquisa era analisar um edifício escolar municipal de ensino fundamental I por meio de seus sistemas construtivo e estrutural utilizado, tendo estudo de caso a E.M. Ivo Garrido, no Parque Residencial Mediterrâneo, região oeste da malha urbana de Presidente Prudente, no Estado de São Paulo.

A metodologia utilizada nesta pesquisa foi qualitativa, partindo de aprofundamento teórico e conceitual, e com levantamentos de campo na edificação analisada, visando a apontar os sistemas construtivo e estrutural da edificação escolar.

\section{DISCUSSÃO}

O processo construtivo pode ser dividido em três fases: concepção execução e utilização, ou apresentada em quatro, incluindo os estudos preliminares (LICHTENSTEIN, 1985; SCHMITT, 1998). No entanto, nesses processos, não pode ser verificada a preocupação com atributos de grande importância: qualidade, integridade e oportunidade (KANGARI e SADRI, 1996).

Assim, os problemas enfrentados pelo processo de construção têm sido focados apenas em relação ao projeto e à execução, ou à redução de custos devido a mudanças econômicas, que proporcionam direcionamentos diversos voltados a métodos alternativos para os processos (SCHMITT, 1998).

Tais alternativas às vezes são positivas, mas se pode verificar a existência de alguns resultados negativos, com consequências em termos de custo do produto final como de desempenho, como poderia ser o caso de patologias construtivas (FRUET e FORMOSO, 1993).

Entretanto, é possível a diminuição de ocorrência de erros com redução de perdas e maximização do tempo de obra, e aumento da produtividade, envolvendo, entre outros aspectos, a definição antecipada de métodos construtivos e de materiais (FARAH, 1990).

Considerando que o foco deste projeto de pesquisa são escolas públicas municipais de ensino fundamental em Presidente Prudente, no estado de São Paulo, é importante verificar os sistemas construtivos utilizados para a execução de seus projetos. Há significativa variação no sistema construtivos, devido à construção em diferentes momentos históricos.

Segundo Faria Filho e Vidal (2000), entre as décadas de 1920 e 1930, os projetos dos grupos escolares sofreram alterações, e os custos de construção foram ampliados, embora o processo construtivo tenha sido mantido: a alvenaria estrutural.

As definições sobre técnicas, método, processo e sistema construtivos são fundamentais no processo de projeto de uma edificação. Segundo Camacho (2006), esses conceitos podem assim 
ser explicados: técnicas construtivas: realização de atividades elementares da construção; método construtivo: conjunto de técnicas construtivas empregado na construção de uma parte da edificação; processo construtivo: particular conjunto de métodos utilizados na construção da estrutura e das vedações; sistema construtivo: processo construtivo de elevado nível de industrialização e de organização.

Especificamente em relação à alvenaria estrutural, Camacho (2006) explica que é o processo construtivo em que os elementos que desempenham a função estrutural são de alvenaria, podendo ser classificada quanto ao processo construtivo empregado, da seguinte forma: alvenaria estrutural armada - processo construtivo no qual os elementos de fechamento (blocos ou tijolos) possuem armadura de aço dispostas nas cavidades desses elementos, posteriormente preenchidas com concreto; alvenaria estrutural não armada - processo construtivo cujos fechamentos também possuem a função estrutural sem armaduras ou acréscimo de concreto; alvenaria estrutural parcialmente armada - processo construtivo no qual algumas paredes são executadas armadas e outras não; alvenaria estrutural protendida - processo construtivo no qual há armadura ativa (protendida) de aço contida no elemento resistente.

Além da alvenaria (estrutural ou não), no processo construtivo pode-se utilizar estrutura em concreto armado, assim como o pré-moldado de concreto. Segundo Bastos (2011), o concreto armado pode ser descrito como construção de elemento estrutural por meio da união do concreto simples - como material resistente à compressão - a um material resistente à tração - armadura envolvido pelo concreto, de forma que ambos resistam solidariamente aos esforços solicitantes.

O concreto (simples) é um material utilizado na construção composto por agregados e aglomerantes. Possui baixa resistência a atração, de tal forma que sua resistência à compressão é dez vezes mais que à tração. Portanto deve ser integrado a materiais de boa resistência a tração (FUSCO, 1977).

Como dito, o concreto armado é a ligação solidária entre o concreto e a armadura, devido à baixa resistência a compressão do concreto, utiliza-se armadura para suprir os forço a tração (FUSCO, 1977). Leva-se em consideração que o aço resiste bem à tração, comumente é o material mergulhado na parte tracionada do concreto, com esta configuração é formado a armadura, que é o princípio do concreto armado (BOTELHO e MARCHETTI, 2015).

Quando os esforço de compressão são resistidos pela armadura, o concreto se torna simples elemento de preservação. Entretanto, é elemento indispensável, já que impede que o aço sofra corrosão e dá proteção mecânica à armadura (FUSCO, 1977). E em relação ao pré-moldado de concreto, é elemento moldado e executado fora do local de utilização definido na estrutura, e fora de usina ou instalações análogas, sem necessidade de pessoal ou laboratório próprios, como acontece com concreto pré-fabricado (ABNT/NBR 9062, 1985).

Considerando o que ocorreu historicamente sobre o processo de elaboração e execução de edificações escolares, a partir de 1930, no governo de Getúlio Vargas, ocorreram mudanças nas diretrizes projetuais, buscando-se construções mais baratas, optando-se por estrutura de concreto armado (FARIA FILHO e VIDAL, 2000).

Nas décadas seguintes, manteve-se a busca pela redução dos custos na construção de novas edificações escolares, e o uso de estruturas em concreto armado aparente ou metálica vinha de encontro a essa expectativa (AZEVEDO, BASTOS, BLOWER, 2007).

Nesse processo de redução de custos e agilização das obras, a partir de meados da década de 1970, o Governo Estadual de São Paulo buscou racionalizar o sistema projetivo, culminando em 1987, com a criação da Fundação para o Desenvolvimento da Educação - FDE (AZEVEDO, BASTOS, BLOWER, 2007). Atualmente, a FDE indica como sistema construtivo a ser utilizado o pré-moldado de concreto.

A partir desse contexto, esta pesquisa buscou analisar uma escola pública municipal de ensino fundamental I em Presidente Prudente, considerando seu sistema construtivo e situação 
atual.

\section{ESCOLA MUNICIPAL IVO GARRIDO}

O projeto e a construção da EM Ivo Garrido datam de 1993, fazendo parte da Secretaria Estadual de Educação. A escola foi municipalizada em 2008. No ano de 2011, a edificação passou por reforma e ampliação, também para adequação às normas de acessibilidade. Alguns levantamentos fotográficos foras realizados na EM Ivo Garrido, o que possibilitou identificar com clareza o sistema construtivo da mesma.

Na figura 1, é possível visualizar o sistema construtivo e a alvenaria de fechamento. Nas figuras 2 e 3, é possível visualizar viga e pilar junto com parede de fechamento. Ou seja, foi possível caracterizar a estrutura da escola como de concreto armado.

Interessante verificar que, quando se fala de pilares, logo se tem a ideia de que os esforços atuantes sobre o mesmo seja somente de compressão, o que na verdade é um equívoco. Justamente porque o pilar sofre ação de compressão, e consequentemente cede lateralmente, gerando distensões que na verdade é o efeito da tração (BOTELHO e MARCHETTI, 2016).

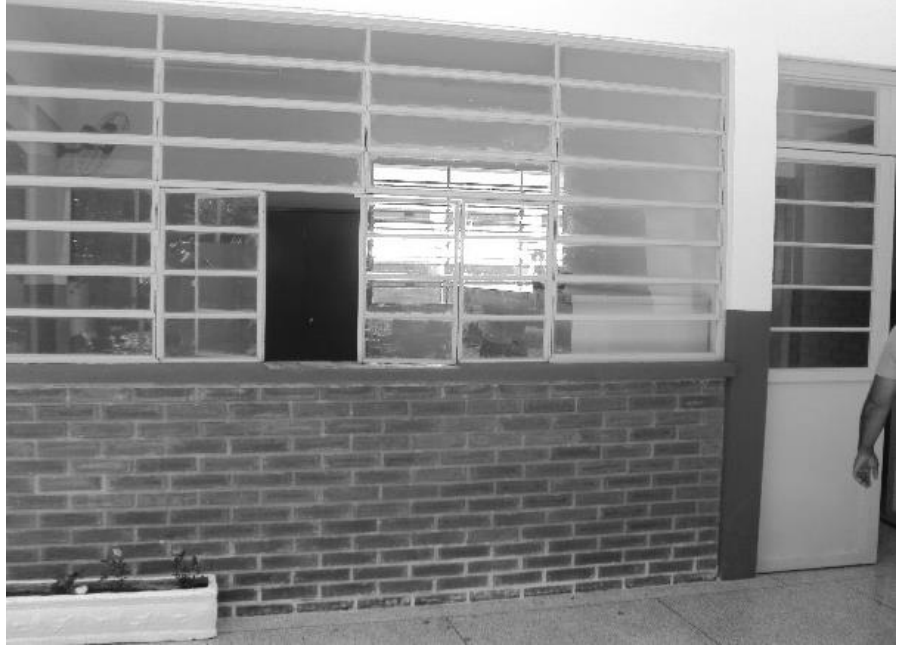

Figura 1. fechamento em alvenaria

Fonte: autores, 2016

Figura 2. viga e pilar

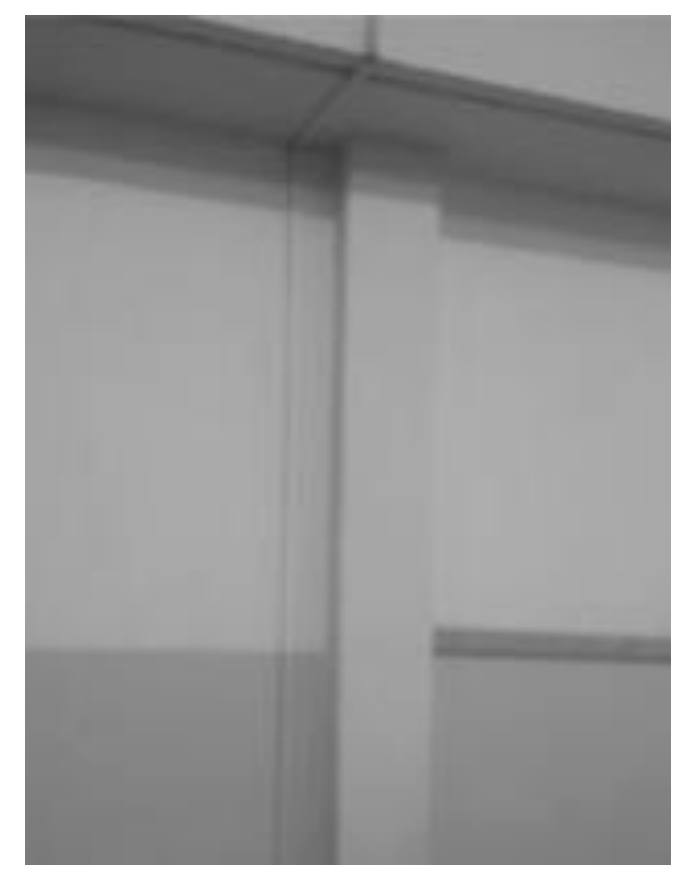

Fonte: autores, 2016 


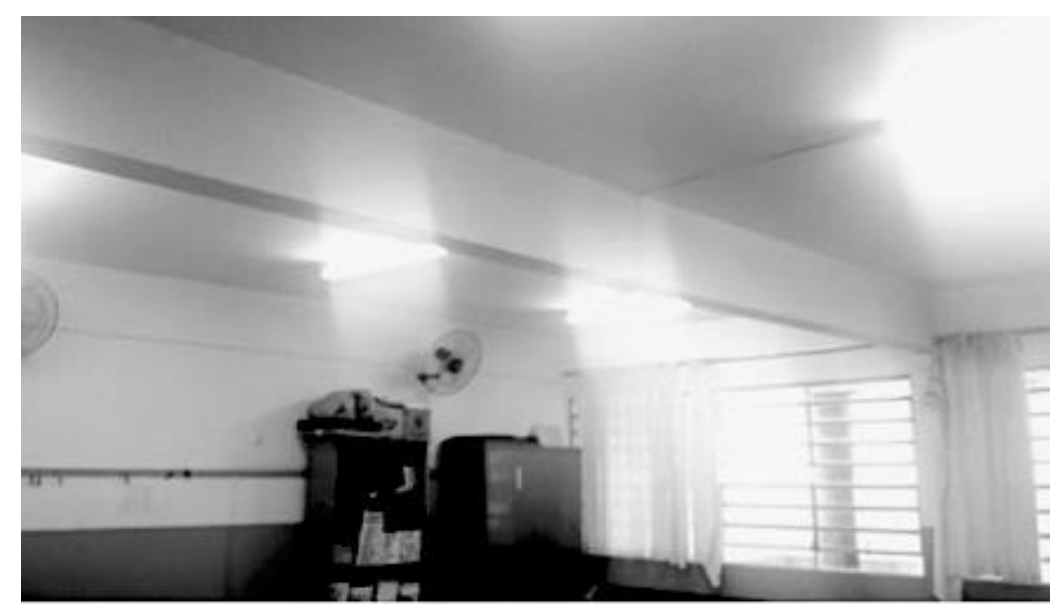

Figura 3. viga aparente

Fonte: autores, 2016

Levando em consideração que o concreto tem uma boa resposta à compressão, utilizado sem o emprego do aço não se obtém resultado satisfatório, pois gera um entorse no pilar. Além de ser preciso uma quantidade elevado do material para ter o mesmo resultado que uma estrutura armada obteria, em outras palavras, seria necessária uma seção maior (BOTELHO e MARCHETTI, 2015).

Mesmo com o inconveniente de uma seção transversal maior, esse tipo de pilar é inviável. Pois a norma NBR 6118, no seu item 17.3.5.3.1, determina o mínimo de 0,4\% de armadura por área da seção do concreto. O que impossibilita a construção de um pilar simples (sem aço) (BOTELHO e MARCHETTI, 2015).

Como visto o emprego do aço é necessário e atua como colaborador para a redução da estrutura, já que desempenhara a característica de receber a compressão que normalmente é efeito pelo concreto, o que deixa as estruturas mais esbeltas. Ainda assim uma pilar com muito aço e pouco concreto eleva os custos. Dessa maneira uma boa relação entre a área do aço e do concreto se dá na ordem $2 \%$. Haja visto que existe uma distensão na estrutura (esforços de tração), o emprego dos estribos irá conter estes deslocamentos laterais. (BOTELHO e MARCHETTI, 2015)

Além disto, os estribos promovem que as barras da armadura permaneça na posição durante a sua concretagem, e consequentemente auxiliando na resistência das barras contra a flambagem, ocorrida dentro do concreto, pela ação de compressão (FUSCO, 1977).

As vigas, são constituída por uma armadura rígida em sua face inferior, afim de suportar os esforços de flexão, e uma armadura formada pelos estribos na sua face superior. Os estribos exercem a imprescindível função de resistir as forças cortante que acontecem na viga. Estes que percorrem de uma face a outra, transpassando a alma da viga (FUSCO, 1977; BOTELHO e MARCHETTI, 2015).

Uma alternativa para a redução da seção transversal de uma viga é colocar armadura na face inferior, resolvendo assim problemas ocasionados em relação a arquitetura em função da altura demasiada das vigas (BOTELHO e MARCHETTI, 2015).

A armadura é colocada na parte inferior da viga para tolerar os esforços de tração, no entanto, quando colocada também na face superior tem por função vencer a compressão, que normalmente é neutralizada pelo concreto. Esta alternativa é possível por que o aço é um material nobre que tem característica primária de ser tracionado, porém, quando solicitado a esforços de compressão tem bom desempenho (BOTELHO e MARCHETTI, 2015).

As lajes são estruturas planas e geralmente retangulares, que suportam cargas verticais acidentais, com espessura definidas pela norma NBR 6118 no seu item 13.2.4.1 (BOTELHO e MARCHETTI, 2015). As lajes sofre o efeito de cargas verticais, no sentido de cima para baixo, 
causando tensões de tração na sua face inferior e compressão na face superior. Portanto, deve ser colocado armadura de aço emergido no concreto (FUSCO, 1977).

\section{CONSIDERAÇÕES FINAIS}

A partir do levantamento e de referencias teóricas, foi possível verificar que a edificação escolar estudada possui sistema estrutural em concreto armado, com vedação das paredes em alvenaria. Verificou-se que o sistema pré-fabricado não foi utilizado, mas sim o moldado in loco. Esse fato contradiz com o sistema indicado pelo FDE, seis anos antes da execução da edificação. No entanto, devido à manutenção que ocorre na edificação, pode-se afirmar a boa situação da edificação, sem patologias aparentes.

\section{REFERÊNCIAS BIBLIOGRÁFICAS}

ASSOCIAÇÃO BRASILEIRAS DE NORMAS TÉCNICAS (ABNT). NBR 9062. Projeto e execução de estruturas de concreto pré-moldado. Rio de Janeiro: ABNT, 1985.

AZEVEDO, G.A.N. Escolas, Qualidade Ambiental e Educação no Brasil: uma contextualização histórica. In.: Caderno de Boas Práticas na Arquitetura - Eficiência Energética nas Edificações. Vol. 8. IAB-RJ. S/D. Disponível em: http://www.gae.fau.ufri.br/arq pdf/artigos/Giselle\%20Arteiro\%20Nielsen\%20Azevedo/Revista\%20 IAB GiselleArteiro2008.pdf. Acesso em 27.01.2015.

AZEVEDO, G.A.N.; BASTOS, L.E.G.; BLOWER, H.S. O moderno já passado - o passado no moderno. In.: III Seminário Projetar. 2007.

BASTOS, P.S.S. Fundamentos do Concreto Armado. Bauru: UNESP, 2011. (Notas de Aula) Disponível em: http://wwwp.feb.unesp.br/pbastos/concreto1/FUNDAMENTOS.pdf. Acesso em: 16.04.2015.

BOTELHO, M.H.; MARCHETTI, O. Concreto Armado - eu te amo. $8^{\text {a }}$.ed. São Paulo: Ed. Blucher, 2015.

CAMACHO, J.S. Projeto de Edifícios de Alvenaria Estrutural. Ilha Solteira: UNESP, 2006. Disponível em:

http://www.nepae.feis.unesp.br/Apostilas/Projeto\%20de\%20edificios\%20de\%20alvenaria\%20estr utural.pdf. Acesso em 17.04.2015.

BRASIL. Constituição Federal Brasileira. 1988.

DELIBERADOR, M.S. O processo de projeto de arquitetura escolar no Estado de São Paulo: caracterização e possibilidades de intervenção. Campinas: UNICAMP. 2010. (Dissertação de Mestrado)

FARIA Fo., L.M.; VIDAL, D.G. Os tempos e os espaços escolares no processo de institucionalização da escola primária no Brasil. In.: Revista Brasileira de Educação. No. 14, PP.19-35. 2000. Disponível em: http://www.scielo.br/pdf/rbedu/n14/n14a03.pdf. Acesso em 06.02.2015.

FARAH, M.F.S. Formas de racionalização do processo de produção na Indústria da Construção. In.: 10‥Encontro Nacional da Construção. Gramado. 1990 
FRUET, G.M.; FORMOSO, C.T. Diagnóstico das dificuldades enfrentadas por gerentes técnicos de empresas de construção de pequeno porte. In.: II Seminário da Qualidade na Construção Civil. Porto Alegre. 1993.

FUNDAÇÃO PARA O DESENVOLVIMENTO DA EDUCAÇÃO (FDE). Governo do Estado de São Paulo. Disponível em:

http://www.fde.sp.gov.br/PagesPublic/InternaProgProj.aspx?contextmenu=novaesc. Acesso em: 15.04.2015.

FUSCO, P.B. Estruturas de Concreto. Recife: McGraw-Hill, 1977.

GOMES Jr, H.A. Vigas Protendidas - estudo da norma e modelagem com auxílio de programa de análise comercial. Rio de Janeiro: UFRJ, 2009. (Monografia de Graduação). Disponível em: http://monografias.poli.ufri.br/monografias/monopoli10007004.pdf. Acesso em: 16.04.2015.

KANGARI, R.; SADRI, S. Building construction primary task models. In.: Proceedings of Construction on the Information Highway. Slovenia. 1996. Disponivel em: http://itc.fgg.unili.si/bled96/papers/kangari.pdf. Acesso em: 18.01.2015.

LICHTENSTEIN, N.B. Patologia das Construções - procedimentos para formulação do diagnóstico de falhas e definição de conduta adequada à recuperação de edificações. São Paulo: EDUSP, 1985. (Dissertação de Mestrado).

MEDEIROS, L.T.D. Gerenciamento de empreendimento - a fase de concepção das construções imobiliária. In.: 10‥ Encontro Nacional da Construção. Gramando. 1990. 